\title{
被 \\ ESTRUCTURA DRAMÁTICA \\ DE MAÑANA SERÁ OTRO DÍA DE CALDERÓN
}

\author{
Aurelio González \\ El Colegio de México \\ [Anuario calderoniano (ISSN: 1888-8046), 1, 2008, pp. 165-181]
}

Mañana será otro día, comedia de Calderón, fue recogida en la Séptima parte de comedias que corregidas por sus originales publicó Juan de Vera Tassis y Villarroel en Madrid en casa de Francisco Sanz en 1683. Este volumen contiene las siguientes obras, todas "grandes comedias»: Auristela y Lisidante, Fuego de Dios en el querer bien, El segundo Scipión, La exaltación de la Cruz, No hay cosa como callar, Celos aun del aire matan, Mañana será otro día, Darlo todo y no dar nada (ya publicada en la Quinta parte), La desdicha de la voz, El pintor de su deshonra, El alcalde de Zalamea y El escondido y la tapada. Como se puede ver por los títulos es un volumen integrado por obras de buen nivel dramático y sólida construcción. La recepción de Mañana será otro día debe haber sido buena y despertado interés pues había sido publicada en El mejor de los mejores libros que han salido de comedias nuevas, en Alcalá, en casa de María Fernández, a costa de Tomás Alfay en 1651, y en Madrid, por María de Quiñones, a costa de Manuel López en 1653. La obra siguió atrayendo lectores, pues en 1715 Juan Sanz publicó nuevamente la parte de 1683 y años después se incluyó en Comedias [...], que saca a luz Don Juan Fernández de Apontes, Madrid, 
Viuda de Manuel Fernández, 1760-1763, y fue reeditada en Barcelona, en la Imprenta de Carlos Sapera en 1766.

Aunque es más dificil rastrear la trayectoria de esta comedia en las tablas, así como su éxito, sabemos que fue representada en 1709 en Perú. En nuestros días fue representada en el Festival del Chamizal en el 2000 por el Teatro Rodante de la Universidad de Puerto Rico, dirigido por Dean Zayas.

A pesar de su intensa presencia editorial en su época, Mañana será otro día es una comedia que ha merecido muy poca atención de la crítica $^{1}$. Tal vez se deba a que es una obra en la cual se ponen a funcionar directamente los esquemas y tópicos de la comedia de capa y espada en una anécdota típica, pero más allá de una visión superficial, la comedia tiene ingenio en su construcción y una sólida estructura dramática, amén de diálogos bien construidos y atractivos para el público.

Revisemos la estructura dramática de la comedia, pero antes hay que aclarar lo que entendemos por este término. Desde mi punto de vista es el sistema de relaciones que se establece entre las distintas partes y elementos de la obra que permiten que el texto literario (en cuanto plasmación de una historia) tenga un funcionamiento teatral y por ende pueda ser representado en un escenario.

En primer lugar hay que tomar en cuenta el reparto, esto es las «personas que hablan». En la comedia, como es muy frecuente en el teatro del Siglo de Oro, se establece una especie de simetría y equilibrio de personajes. En Mañana será otro día aparecen tres damas: doña Beatriz, doña Elvira y doña Leonor y tres caballeros (aunque sólo dos de ellos están definidos en la Séptima Parte como galanes) don Fernando, don Juan y don Diego, cada uno de ellos tiene una figura de contraste y equilibrio simétrico: a don Fernando lo acompaña Roque, el típico criado gracioso; a don Juan el capitán Clavijo, antiguo soldado de experiencia y por tanto igualmente consejero, y a don Diego, el caballero de función secundaria, le acompaña su amigo Fabio. El gracioso Roque tendrá como contraparte a Juana, la criada de doña Beatriz, y ésta a su vez tendrá simétricamente su equivalente en Isabel, la criada de Leonor. Finalmente en el punto de equilibrio y de confluencia de las acciones está don Luis, que sería el papel habitual de

${ }^{1}$ López, 2003. 
viejo o «barba». En la comedia también tienen papel otros personajes con acciones puntuales que son necesarias por ser operativas para la trama: la criada Inés, el escudero Ginés, un escribano y un alguacil. La trama pide además una escena en la que deben aparecer «los más que se pudiere». El reparto de personajes se corresponde bastante bien con lo que sería la composición estándar de una compañía de nivel. La acción, aunque no se especifica a lo largo del texto, está marcada que tiene lugar en un ámbito urbano específico y por demás conocido: Madrid.

Los personajes además están interrelacionados entre sí de la siguiente forma:

Don Juan es hijo de don Luis, hermano de doña Beatriz y corteja a doña Elvira y doña Leonor.

Doña Beatriz es hija de don Luis, hermana de don Juan, amiga de doña Elvira y prometida de don Fernando.

Don Fernando es prometido de doña Beatriz y primo de doña Leonor.

Doña Leonor es cortejada por don Juan, es prima de don Fernando y amiga de doña Elvira.

Doña Elvira es cortejada por don Juan y es amiga de doña Beatriz y doña Leonor.

Don Diego corteja a doña Elvira.

Esta multiplicidad de relaciones es la que permite una intriga compleja y que en el marco de la temática de capa y espada se pueda usar tranquila y efectivamente el recurso del «enredo», tan socorrido por apreciado por el público de las comedias áureas.

En la estructuración dramática del texto literario es fundamental la creación espacial ya que la obra de teatro, desde su génesis, se concibe como un texto destinado a la representación y ésta se proyecta de acuerdo con las convenciones escénicas de su tiempo. Por lo cual la obra teatral se construye a partir de una doble textualidad, por una parte el texto dramático que recoge los parlamentos de los personajes y por otra parte el texto que implica el montaje escénico. El dramaturgo controla la puesta en escena de su obra por medio de marcas —didascalias — incluidas en el texto de manera implícita o 
explícita $^{2}$ que tienen que ver tanto con las acciones como con la creación del espacio. Esto es especialmente importante en el teatro del Siglo de Oro ya que como se ha dicho en varias ocasiones se trata de una manifestación teatral con una escenografia de palabras pues la ubicación del espacio dramático, cuando menos en el caso de las comedias hechas para ser presentadas en el espacio teatral del corral rara vez recurre a la construcción escenográfica o al telón pintado.

Por otra parte hay que tener presente, como es bien sabido, que una de las características de la dramaturgia barroca es su inmensa potencia para dramatizar, esto es para hacer teatral, cualquier hecho tanto de la vida cotidiana y las acciones mínimas como las grandes hazañas históricas o épicas, incluyendo la tradición literaria y la devoción religiosa. Calderón no es ajeno a esta característica que explica la variedad temática de su teatro, pero esta potencia implica la necesidad de crear una serie de códigos y convenciones, acorde con una poética dramática, para la representación de las historias (reales o ficticias) convertidas en hecho teatral.

La relación que existe entre el diálogo y las acotaciones (relación que establece el hecho de la representación) ha sido vista en distintas formas. Ingarden utiliza los términos Haupttext («texto primario») y Nebentext ("texto ancilar») ${ }^{3}$ para distinguir entre el diálogo de los personajes y las indicaciones escénicas, su selección de términos implica un paralelismo y por lo tanto dos sistemas significativos complementarios e interdependientes. Por su parte, Esslin considera que como el teatro es en esencia "acción mimética» ${ }^{4}$ existe una primacía del Nebentext de Ingarden sobre el Haupttext. Veltrusky, que reconoce las acotaciones como parte de la estructura literaria y con una función muy importante en la construcción semántica, considera que dichas indicaciones, en relación al diálogo, tienen una posición subordinada 5 .

Por otra parte «todas las relaciones entre los personajes se proyectan en el espacio» ${ }^{6}$ que es donde se mueven los actores, esta dimen-

2 Sobre la doble textualidad de la obra de teatro pueden verse los trabajos de Bobes, 1987; Ubersfeld, 1989; y sobre el desarrollo del concepto de didascalia, Hermenegildo, 1991.

${ }^{3}$ Ingarden, 1973, p. 208.

${ }^{4}$ Esslin, 1987, p. 83.

${ }^{5}$ Veltrusky, 1997, p. 47.

${ }^{6}$ Veltrusky, 1997, p. 40. 
sión es la que determina la organización de la obra; así se origina lo que Zich llamó «espacio dramático» entendido como un conjunto de fuerzas inmateriales que va cambiando en el tiempo junto con las transformaciones de esas fuerzas ${ }^{7}$.

Teatralmente el espacio puede ser comprendido desde varias perspectivas. Obviamente existe un espacio fisico (el escenario o tablado) en el cual se desenvuelven los personajes y que puede ser definido como el espacio escénico; por otra parte en ese espacio físico se crea un espacio de la ficción que es el espacio dramático. Además, hay que entender un espacio complejo que engloba el espacio de la representación y el que ocupa el espectador y que podemos llamar espacio teatral ${ }^{8}$.

Por otra parte el espacio puede entenderse, como lo hace Corvin, desde una doble modalidad en su funcionamiento: por un lado desde el punto de vista de su dimensión real (bajo la forma de gestos y movimientos del actor en las tres dimensiones: altura, anchura y profundidad) en el escenario, y desde una dimensión virtual por la evocación, tanto de palabra como de gestos, de espacios ausentes de varios tipos: en primer lugar, un espacio invisible, pero coextensivo del espacio escénico (hoy ocupado por los bastidores y desahogos, y antes por el vestuario y demás cámaras ocultas a la vista del público), además, tenemos un espacio distante, incluso situado en otro tiempo, el pasado, que puede ser evocado, y finalmente un espacio afin configurado por la palabra9.

También es necesario recordar algunos conceptos a propósito de la dramaturgia calderoniana en general. Por una parte se considera que las máximas figuras del teatro clásico español son Lope de Vega y Calderón, pero esta síntesis más bien parece que busca determinar «los dos polos de una misma corriente histórica. Al Lope volcado hacia afuera, rico de pasión vital, se une, como la otra cara de un mismo torso, el Calderón volcado hacia adentro, rico de pasión intelectual» ${ }^{10}$. Esta visión ha llevado a parte de la crítica a centrar erróneamente sus puntos de vista en un Calderón esencialmente antilopista y antivitalista. Ruiz Ramón, aunque advierte de lo falso de esta dicotomía y

\footnotetext{
${ }^{7}$ Zich, 1931, p. 246.

${ }^{8}$ Ver Pavis, 1985; y Massip, 1992.

${ }^{9}$ Ver Corvin, 1997, pp. 203-204.

10 Ruiz Ramón, 1971, p. 248.
} 
aunque reconoce que las comedias de Calderón son tan abundantes como sus dramas, dedica en su historia del teatro un par de páginas escasas a hablar de sus comedias cuando ha dedicado cuatro decenas a los dramas. Entre los conceptos que expresa a propósito del Calderón de comedia dice que «lleva al máximo de estilización formal y de complejidad escénica los temas propios - típicos y tópicos- de ambiente cortesano, urbano o rural, y de intención éticamente ejemplar o finalmente costumbrista, específicos de la comedia de "capa y espada" o comedia de "ingenio" tan solicitadas por los directores de compañías». Un aprobador de su teatro dijo que Calderón «elevó la comedia a ciencia en perfecto silogismo» y como dice Valbuena Prat en este género destaca por «Su especial aspecto de la intriga y de los arquetipos o personajes, los recursos de la acción, el estilo, las figuras de graciosos y criadas a las danzas y peripecias de escondidos y tapados» ${ }^{11}$.

A propósito de la habilidad de Calderón como comediógrafo no hay que olvidar que, antes de cumplir treinta años, ya había escrito dos grandes comedias que son joyas de la dramaturgia áurea: La dama duende, representada en 1629 y publicada en 1636, y Casa con dos puertas mala es de guardar, llevada a la escena en 1629 y publicada en Valencia en 1636, en la Parte veintinueve de comedias de diferentes autores. En Mañana será otro día se muestra esta maestría en la habilidad para manejar los tópicos de la comedia de capa y espada y el enredo.

No hay que olvidar (a pesar de que frecuentemente lo hacen algunos críticos y directores contemporáneos) cuando se revisan los elementos constructivos de las comedias, que se trata de obras que hay que entender como una «unidad de funcionamiento lúdica cuya calidad máxima radica en la construcción de un mecanismo de intriga esencialmente divertido» ${ }^{12}$. También hay que tomar en cuenta que estos elementos hay que revisarlos en una doble perspectiva, por un lado tenemos el juego semántico de diálogos y términos empleados en éstos, la intertextualidad que representa un papel importante $-\mathrm{y}$ que en muchas ocasiones es la que escapa al espectador contemporáneo de estas comedias-, y el chiste propiamente dicho, y por otro, igualmente importante, hay que tener en cuenta en la construcción lúdica, la alteración que sufre un texto en su captación según el contex-

11 Valbuena Prat, 1969, p. 270.

12 Valbuena Prat, 1969, p. 177. 
to escénico en que está dicho, así, muchas veces la gracia de un parlamento radica simplemente en que es un aparte, o en que se trata de diálogos en contrapunto (pienso, por ejemplo, en tantos diálogos paralelos de criados y criadas y damas y galanes) entre niveles sociales o tipos de personajes. Muchas veces la comicidad radicará esencialmente en el texto espectacular, esto es en el espacio, vestuario y movimientos que se crean sobre el texto dramático.

Veamos ahora la estructuración dramática de esta comedia a partir de la creación del espacio dramático. La comedia se abre in media res con una mujer y un hombre dialogando, inmediatamente se identifican estos personajes ya que a la mujer se le llama Beatriz y se señala que el hombre es el padre de la mujer, también se ubica la acción en la casa de los personajes, el que la acción tenga lugar en un interior estará construido escénicamente por el vestuario de los personajes. A continuación el personaje masculino tiene un largo parlamento en el cual proporciona los antecedentes de la situación, menciona otros personajes que se identifican con su nombre: Juan de Leyva, hermano de Beatriz, y Fernando de Cardona, prometido de ésta.

A continuación se crea un espacio coextensivo al escénico con ruidos y posiblemente voces con la llegada de Elvira:

$\begin{array}{ll}\text { BeAtriz } & \begin{array}{l}\text { Ruido dentro. } \\ \text { JuAna }\end{array} \\ & \text { En casa, por esa puerta } \\ & \text { que a la calle cae del Carmen, } \\ & \text { señora, una silla entra. } \\ \text { BeAtriz } & \text { Pues yo no estoy avisada, } \\ & \text { no sé qué visita sea. }(\mathrm{I}, \mathrm{p} .758)^{13}\end{array}$

Este espacio aledaño es importante para la tercera jornada donde hay un encuentro de los personajes en ese lugar. En el diálogo siguiente las damas Beatriz y Elvira plantean que van a salir de noche

13 Todas las citas de Mañana será otro día están tomadas de Pedro Calderón de la Barca, Obras completas. Comedias, ed.Valbuena Briones, 1960, sin embargo, no se toman en cuenta las acotaciones agregadas por el editor y se tiene presente la edición de la Séptima parte de comedias. En adelante sólo se indica entre paréntesis el número de jornada en romanos y la página en arábigos. 
y encubiertas, principio esencial del enredo. Los personajes se van del tablado, cerrando una secuencia y se abre otra con la entrada de nuevos personajes:

DON JUAN

Vanse, $y$ salen don Juan, y Leonor con manto, y una criada.

LEONOR

Licencia me habéis de dar para que os vaya sirviendo.

Antes rogaros pretendo

que os quedéis, por excusar

el que no demos los dos

que decir. (I, p. 761)

La presencia de la dama tapada con manto y acompañada por una criada, que así lo pide la didascalia explícita, ubica la acción en un nuevo espacio exterior, podemos suponer, de acuerdo con la lógica escénica de la época que se trata de una calle. Esto se hace evidente cuando Leonor dice:

LEONOR Si hoy de mi casa salí tapada, a pie y sola, fue porque fui cerca. (I, p. 761)

El desplazamiento espacial está dado por la salida de los personajes del espacio escénico y la entrada de nuevos personajes. Cuando se van don Juan y el Capitán Clavijo dejan vacío por un instante el tablado y entran, según pide la acotación,

ELVIRA

Vanse, y salen doña Elvira y doña Beatriz disfrazadas y tapadas.
¿Ves como no ha tenido
ningún inconveniente haber venido
hasta aquí disfrazadas?
Pues saliendo de casa bien tapadas
con habernos entrado
en casa de Leonor, a quien fiado
habemos el secreto,
mudamos traje. ¿Ves como en efeto
dejando del convento en esa puerta
el coche, hemos llegado hasta esta huerta, que es donde yo le dije, que estaría sin riesgo alguno? (I, p. 762) 
El señalar explícitamente el lugar donde se encuentran es obligado por el súbito cambio de espacio y de tiempo. El atuendo de las damas es correspondiente con el lugar y la situación. Con estos recursos no es necesaria la construcción escenográfica. El tipo de vestuario del disfraz queda al arbitrio del «autor» o director, pero el manto es obligado para evitar el reconocimiento de las mujeres por los otros personajes.

La secuencia del duelo con espadas entre don Juan, el capitán Clavijo, don Diego y Fabio tiene su desenlace nuevamente en un espacio extensivo del escénico:

Métenlos a cuchilladas don Juan, y el Capitán.

Dentro.

¡Cuchilladas, cuchilladas!, señor Soto ${ }^{14}$, corra presto, ya que en aquesta ocasión en estas huertas nos vemos, venga, escribirá la causa.

Sale un escribano. (I, p. 764)

El cambio espacial lo marca la salida de los personajes y la entrada de Leonor al tablado sin manto y pidiendo luces, forma que, de acuerdo a los usos de la época, corresponde al espacio interior de su casa, así como el momento, velas u otro tipo de iluminación crean así escénicamente el espacio dramático:

Vanse acuchillando, y salen Leonor y Isabel con luces.

LEONOR ¿Isabelilla?

ISABEL

LEONOR ¿Señora?
Pon unas luces ahí.
Ya están las luces aquí.
Pues salte allá fuera ahora. (I, p. 766)

ISABEL

LEONOR

El espacio interior se convertirá en exterior cuando doña Beatriz sale huyendo de la casa de Leonor y se encuentra con Roque y don

${ }^{14}$ La edición de Valbuena pone Ortiz. 
Fernando que en su diálogo han creado la ubicación espacial en una calle ya que buscan la casa de Leonor.

El mecanismo de salida del tablado por una puerta y entrada por otra de los mismos personajes o también el desplazamiento en el mismo tablado permiten crear un nuevo espacio, el cual se hace explícito en el diálogo. Así se van doña Beatriz, don Fernando y Roque y cuando vuelven a entrar dicen:

BEATRIZ

En esta calle que veis me dejad, que mi temor seguro está, como aquí os quedéis, por si escucháis voces.

FERNANDO

Cuanto me mandáis me toca observar a mí. (I, p. 769)

Así termina la primera jornada. Es fácil de ver la confusión que se crea con las tapadas, así como los deslizamientos espaciales que dan agilidad a la trama y que necesariamente requieren para poder mantener el interés del público un diálogo ágil e ingenioso.

La segunda jornada se inicia con un diálogo entre don Juan y el capitán Clavijo en que explícitamente señalan que están en la calle ante la casa de don Luis. Se abre una puerta y don Juan entra. La siguiente escena es el interior de la casa creado por la presencia de doña Beatriz y su criada Juana, don Juan vuelve a aparecer por la puerta completando la acción que había iniciado al irse del tablado por la puerta:

Vase el capitán, y salen Beatriz, y Juana.

JUANA ¿Tan aprisa te levantas?

BeATriz Sí, que no hay potro peor que el lecho a quien no descansa.

Juana Pues ¿qué tienes?

BeATriz Si te he dicho cuánto ayer... pero quién anda, mira ahí afuera.

Don JuAN Yo soy, y solo el tiempo que tarda 
en hallarte mi desdicha,

tarda en matarte, tirana ${ }^{15}$. (II, p. 771)

La indicación de Beatriz a Juana «mira quién anda» implica, por lógica escénica, que ha tenido que oírse algún ruido y que posiblemente es Juana la que abre la puerta para que entre don Juan, cerrando como decíamos antes, el desplazamiento espacial iniciado por don Juan al salir del tablado por una de las puertas.

La salida de los personajes dejando vacío el tablado implica un nuevo espacio, ahora la casa de Leonor, marcada por la entrada de ésta acompañada por don Fernando, su primo y prometido de doña Beatriz, como ya dijimos:

Vase, y sale don Fernando y Leonor.

LEONOR

Huésped que sin avisar, tarde y a deshora viene, si mala posada tiene, de sí se podrá quejar.

FERNANDO Esfera tan singular vuestra casa es, Leonor bella, que el sol fuera huésped della, sin menguar de su arrebol, si ya no temiera el sol con vos parecer estrella. (II, p. 773)

Roque y don Fernando saldrán del espacio que se ha identificado como la casa de Leonor y al regresar al tablado, el nuevo espacio es ahora exterior: la calle de la casa de don Luis, lo cual hará explícito el gracioso Roque:

\section{Vuelve Roque.}

Roque No solamente he sabido cuál es de don Luis la casa,

pero a sus umbrales mismos estamos $^{16}$. (II, p. 775)

15 La edición de Valbuena dice "mi rabia».

16 La edición de Valbuena dice «estás». 
La escena repite el procedimiento anterior de entrada de un personaje por una puerta y aparición de regreso, por lógica escénica por la misma puerta, pero el espacio ha cambiado pues están otros personajes y es el interior de la casa. Estableciendo un paralelismo ahora se encuentran en la escena don Fernando y doña Beatriz, como antes se había encontrado doña Beatriz con su hermano don Juan. El recurso ahora no es un ruido que expande el espacio sino un recurso diegético por el que el personaje nos dice lo que está viendo en otro espacio:

BEATRIZ

JUANA

BeATriz

JUANA

BEATRIZ

JUANA

Aquel que hacia allí miro, el forastero es de quien hablaba Juana contigo. Hasta aquí, señora, se entra.

Sin duda me ha conocido $\mathrm{y}$ viene a pedir las gracias de las finezas que hizo por mí.

$$
\begin{aligned}
& \text { Necedad, señora, } \\
& \text { era el haber presumido } \\
& \text { que anoche no te siguiese. }
\end{aligned}
$$

Yo no lo dudo, aunque admiro, que entrando yo por esotra puerta anoche, haya venido hoy a buscarme por esta.

¿Tan dificultoso ha sido saber que en casa hay dos puertas? (II, p. 775)

El siguiente desplazamiento nos lleva a un nuevo espacio, que por la potencia del teatro barroco no tiene diferencia escenográfica con ninguno de los otros que se han creado hasta el momento, pues toda la ubicación escenográfica ha sido de palabras. Ahora la acción se sitúa en casa de doña Elvira, el recurso es simple: basta que aparezcan las damas con manto y nos digan donde están:

Vanse, $y$ salen Elvira, $y$ Leonor con manto.

ELVIRA

Dime, Leonor, la ocasión

con que hoy a verme has venido, 
que parece que has traído

alguna grave pasión.

LEONOR Yo vengo a saber quién es aquella gallarda dama tu amiga. (II, p. 778)

El cambio a la casa de doña Leonor es aun más sintético, pues la dama en cuestión se va de casa de doña Elvira y en la siguiente secuencia está hablando con su primo don Fernando, lo que habrá cambiado es su apariencia: no usará manto pues está en su propia sala.

El recurso de hacer un camino para indicar un cambio de espacio, esto es escenificar el desplazamiento, también se utiliza en esta comedia, lo cual indica por un lado el conocimiento técnico de Calderón, el cual está fuera de duda, y su habilidad para dar variedad a la obra:

ROQUE

FERNANDO
Pero señor, mira

que ahora vamos por la calle;

no vayas con tanta prisa,

que echan de ver los que pasan,

que suegros umbrales pisas.

Ve despacio.

que no es mi voluntad mía? (II, p. 782) ${ }^{17}$

En la siguiente escena entrarán por una puerta don Luis, doña Beatriz y Juana y por la otra don Fernando y Roque y el espacio será el interior de la casa «los suegros umbrales» que decía Roque de don Luis. Después de decir don Fernando que se regresa sin que haya boda, la acción se traslada a la calle, esto se logra con un breve diálogo entre doña Beatriz y Juana una vez que han salido don Fernando y Roque. Cuando se van las mujeres y salen al tablado estos últimos el espacio es otro y por coherencia temporal la calle en la cual se encontrarán con los personajes del ardid urdido por doña Beatriz:

Sale por una puerta un escudero, con un papel, y por otra Juana, con un azafate cubierto, $y$ un papel. (II, p. 783)

17 Esta secuencia no aparece en la Séptima parte. 
La jornada tercera se inicia con doña Beatriz, Juana e Inés con mantos, señal de que están en un espacio exterior, esto es la calle.

El siguiente es en casa de don Luis y se marca de quién es el espacio por la diferencia entre traer manto y no traerlo de doña Elvira y doña Beatriz:

Vanse, $y$ sale por una parte Elvira con manto, y Beatriz, y Juana por otra. (III, p. 789)

Más adelante tendrá lugar el encuentro en el espacio ubicado en la primera jornada de la casa vecina al que llegan don Fernando y Roque guiados por Juana (III, 792) el cual se subraya que es desconocido y que tiene una reja, elemento absolutamente factible en la construcción habitual del tablado del corral, sin necesidad de mayores complicaciones escenográficas. Incluso podría representarse desde uno de los balcones superiores.

Sale Beatriz a una reja.

BEATRIZ

¡Don Fernando!

ROQUE

Allí a una reja

que se divisa en un patio, oí la voz.

FERNANDO

Dos cosas son, señora, las que yo extraño; una, oír mi nombre; y otra, dentro en vuestra casa hablaros por reja. (III, p. 793)

La escena concluye con cuchilladas: «Salen los que pudieren con las espadas desnudas» (III, p. 795 $)^{18}$ y la escena se desplaza al interior de la casa de don Luis donde se utilizará una de las puertas para que un personaje escuche lo que se dice dentro, en este caso Roque:

Roque ¿Escuchaste?

FERNANDO Sí.

18 La edición de Valbuena dice «todos los que pudieren». 
Elvira Escondido don Fernando.

FERNANDO

¡Válgame el cielo! (III, p. 796)

La acción ya no se desplazará a otros espacios y solamente implicará al final el rompimiento del espacio dramático, esto es del espacio de la ficción, para regresarnos al espacio escénico como espacio de la representación con el texto final de Roque que no se limita a pedir perdón por las faltas cometidas sino que aclara y puntualiza los detalles sueltos que pudieron haber quedado de las acciones llevadas a cabo:

Roque Esperen vuesas mercedes, que decir tres cosas falta.

Ya se acordarán que hubo en la primera jornada un don Diego, y que le dieron en ella una cuchillada; él se la ha estado curando, y por eso de aquí falta. También hubo una Leonor introducida en la farsa, y no está aquí, porque fuera malo el salir de su casa a estas horas; de estos dos cuentan mil historias largas que se casaron también. Si aguardan que entre en la danza una maleta perdida, desta sola no se halla tradición: aquesto he dicho porque no me quede nada que decir: si vuesarcedes de la comedia se agradan, mañana será otro día, para que vengan a honrarla. (III, p. 799)

Esta revisión de la manera en que se crea el espacio dramático sobre el escenario nos permite constatar, además de la habilidad de Calderón para introducir en el texto dramático las didascalias implícitas que construyen el espacio, cómo el espacio es un elemento impor- 
tante en la construcción del enredo, así como parte importante de la estructura dramática (en cuanto esta es un sistema de relaciones) que permite el funcionamiento de la obra sobre el escenario. Los elementos y recursos hasta aquí señalados en buena medida determinan la agilidad y vivacidad de la comedia y marcan el comportamiento de los personajes más allá de su definición genérica como damas, graciosos, criadas o galanes. Al mismo tiempo este manejo, hasta cierto punto marcado por el virtuosismo, es el que da individualidad y personalidad propia a la pieza, que por estar construida a partir de tópicos, de no tener este tipo de manejo podía ser anodina y carente de interés para un público muy acostumbrado a la presencia de dichos tópicos en la comedia.

También la comprensión de estos elementos, las didascalias y la construcción rápida del espacio como parte de la estructura dramática nos permite entender la comedia desde una perspectiva escénica que va más allá de la lectura rápida y superficial que olvida la especificidad del género dramático.

En este sentido, para terminar, y a propósito de Mañana será otro día, quiero hacer mías las siguientes palabras de Aurora Egido: «Una representación teatral es un fenómeno efímero y la escenografia es el arte de lo provisional. Cuando el espectáculo ha terminado no queda de él sino el recuerdo» ${ }^{19}$. Sólo que en este caso la escenografia ha sido hecha de palabras.

19 Egido, 1995, p. 262. 


\section{Bibliografía}

Bobes, M. del C., Semiología de la obra dramática, Madrid, Taurus, 1987.

Calderón de la Barca, P., Mañana será otro día, en Obras completas. Comedias, ed. Á. Valbuena Briones, Madrid, Aguilar,1960, pp. 759-790.

- Séptima parte de comedias que corregidas por sus originales publicó Juan de Vera Tassis y Villarroel en Madrid en casa de Francisco Sanz en 1683.

Corvin, M., "Contribución al análisis del espacio escénico en el teatro contemporáneo», en Teoría del teatro, comp. M. del C. Bobes, Madrid, Arco/Libros, 1997, pp. 201-228.

EgIdo, A., "La fiera, el rayo y la piedra. Su puesta en escena según la edición de 1664», en El gran teatro de Calderón. Personajes, temas, escenografía, Kassel, Reichenberger, 1995, pp. 235-262.

EssLin, M., The Field of Drama, London, Methuen, 1987.

Hermenegildo, A., «Los signos condicionantes de la representación: el bloque didascálico", en Critical essays on the literatures of Spanish America, ed. L. T. González del Valle y J. Baena, Boulder, Colorado, Society of Spanish and Spanish-American Studies, 1991, pp. 121-131.

Ingarden, R., The Literary Work of Art, Evanston, Northwestern University Press, 1973.

López, N., «Los decorados y los estilos de actuación en Mañana será otro día de Calderón", en Published proceedings of XIII Anglo German Colloquium on Calderón, Firenze, Universitá degli Studi di Firenze, 2003, pp. 23-36.

Massip, F., El teatro medieval, Barcelona, Montesinos, 1992.

Pavis, P., Voix et images de la scène, Lille, Presses Universitaires de Lille, 1985.

Ruiz Ramón, F., Historia del teatro español, Madrid, Alianza, 1971.

Ubersfeld, A., Semiótica teatral, Madrid, Cátedra / Universidad de Murcia, 1989.

Valbuena Prat, Á., El teatro español en su Siglo de Oro, Barcelona, Planeta, 1969.

Veltrusky, J., «El texto dramático como uno de los componentes del teatro», en Teoría del teatro, comp. M. del C. Bobes, Madrid, Arco/Libros, 1997.

Zich, O., Esthétique de l'art dramatique. Dramaturgie théorique, Praga, Melantrich, 1931. 
